\title{
Predictors for Salivary Gland Cancer Recurrence at Two Tertiary Hospitals in Saudi Arabia
}

Thamer Alraddadi $^{1}$, Saleh Aldhahri ${ }^{1}$, Jabir Alharbi ${ }^{2}$, Moayyad Malas ${ }^{3}$, Tahera Islam ${ }^{4}$, Ahmad Altuwaijri 1 , Khalid Al-Qahtani ${ }^{1}$

1. Otolaryngology, King Saud University, Riyadh, SAU 2. Otolaryngology, Majmaah University, Riyadh, SAU 3. Otolaryngology, King Khaled Hospital, King Abdulaziz Medical City, Jeddah, SAU 4. Miscellaneous, College of Medicine and Research Center, King Saud University, Riyadh, SAU

Corresponding author: Thamer Alraddadi,dr.thamer.f.alraddadi@gmail.com

\section{Abstract \\ Background}

Tumors of salivary glands are enlarged as a low-risk mass and mostly benign in nature. The treatment of salivary gland malignancy remains quite challenging because of its relative infrequency, unreliable biological manners, and risk of re-emergence. For effective treatment planning, prediction of factors associated with the recurrence of salivary gland malignancy is essential.

\section{Aim}

The objective of this study was to identify the factors associated with recurrence of salivary gland malignancy at two tertiary hospitals in Saudi Arabia.

\section{Material and methods}

A cross-sectional study was conducted at two tertiary hospitals in Saudi Arabia, where data of patients were recorded from the medical records of hospitals from 2012 to 2018. 63 patients who were diagnosed with salivary gland malignancy, whether originated from parotid, submandibular, sublingual, and minor salivary glands were included in the study. Descriptive statistics are shown in mean, frequency, and percentages, while comparative analysis was done using the Chi-square test, where $p<0.05$ is considered significant.

\section{Results}

This study included 63 participants. The majority of malignant salivary gland cancers arise from the parotid gland (47.6\%), and mucoepidermoid carcinoma was the commonest form of malignancy in $36.5 \%$ of the studied population. Out of 63 patients, 17 had a recurrence of cancer, and the initial advanced stage of the disease is apparently associated with the re-emergence of salivary gland cancer.

Received 07/26/2019

Review began 07/29/2019 Review ended 07/30/2019 Published 07/31/2019

\section{() Copyright 2019}

Alraddadi et al. This is an open access article distributed under the terms of the Creative Commons Attribution License CC-BY 3.0., which permits unrestricted use, distribution, and reproduction in any medium, provided the original author and source are credited.

\section{Conclusion}

The initial advanced stage of cancer has a significant role in the recurrence of salivary gland malignancy. As salivary gland malignancy is rare and has unreliable behavior, establishing an adequate treatment plan prediction for recurrence is essential.

Categories: Otolaryngology

Keywords: salivary gland cancer, recurrence, predictors, advanced stage

\section{Introduction}

Tumors of salivary glands are enlarged as a low-risk mass, with most of them benign in nature and only a few malignant [1]. The cancers of salivary glands are usually infrequent, occurring in 0.6-1.4 per 100,000 and may originate from either major or minor salivary glands. It accounts for $0.5 \%$ of all cancers and $5 \%$ of cancers associated with head and neck [2-4]. There are approximately 40 histological types of salivary glands tumors, with some of them astonishingly atypical. The prevalence of salivary gland benign tumors is about $54 \%$ to $79 \%$ and the malignant tumors about $21-46 \%$ [5]. Usually, the clinical behavior of the salivary gland tumors depend upon histology, grading, and TNM staging and classified into low-grade, intermediate, and high-grade categories [6]. In previous studies, the degree of differentiation correlates significantly with the frequency of lymph node metastases, the degree of local invasion, which further affects the overall survival rate [7-8]. Unlike most of head and neck cancers that generally arise due to adverse habits of smoking and drinking, the etiologic factor behind salivary gland malignancy remains unclear [9]. Radiation exposure during the treatment for head and cancers, occupational exposure, previous history of cancers in other parts of body, Epstein-Barr Virus infection, immunosuppression, and HIV infections may be considered as menacing factors for salivary gland malignancy [10-13]. For that reason, diagnosis, the judgment of prognosis and choice of treatment in patients with salivary gland malignancies need to be enhanced [14]. 
In salivary gland tumors, multiple clinical and pathological variations present in major and minor salivary glands from different geographic areas. Studies from Iran and Sri Lanka reported a high incidence of malignant cancer in salivary glands [15-17] while the opposite has been reported from the USA and China [18-19]. Salivary gland cancers are relatively rare with unreliable behavior, considerable variations in racial and geographical distribution and risk of recurrence which makes the treatment quite challenging. The inadequate data are available in regards to the factors associated with the recurrence of salivary gland malignancy. Thus, the purpose of this study was to identify and highlights the factors associated with recurrence of salivary gland malignancy in two tertiary (national) hospitals in Saudi Arabia.

\section{Materials And Methods}

A cross-sectional study was conducted on all patients discussed in the tumor board with salivary gland tumors from 2012 to 2018 in two tertiary hospitals in Saudi Arabia. The centers included in this study are located in the central region in the Kingdom of Saudi Arabia and are considered the main referral centers for head and neck cancer patients from around the country, especially those with advanced disease and comorbidities. The medical records of the included patients were retrieved from the hospitals' medical record department, and data of patients were recorded in a structured manner. Ethical approval for the study was obtained from the institutional ethical committee and administrative department of the hospitals. All patients diagnosed with salivary gland malignancy originating from the parotid, submandibular, sublingual, and minor glands were included in the study. Patients who lost follow-up or have incomplete data were excluded from this study.

Data collection included participants' demographics and tumor data. Age, gender, stage of cancer, and geographic location of the patients were considered as credential factors for the possibility of recurrence of the salivary gland tumors. Also, disease characteristics, such as patients' presenting symptoms, site of lesions, incision biopsy results, histopathology, and presence of recurrence were recorded. TNM staging was performed according to the Seventh Edition of the American Joint Committee on Cancer (AJCC), Cancer Staging Manual [20]. Statistical analysis was done using Statistical Package for the Social Sciences (SPSS) software, version 20. Descriptive statistics are shown as mean, frequency, and percentages, while comparative analysis was done using the Chi-square test. Statistical significance was considered when $\mathrm{p}$ value $<0.05$.

\section{Results}

Initially, 101 patients were recruited for the purpose of this study, but 38 were excluded who were not available for follow-up. The total sample size comprised 63 patients. Approximately half of the participants were females (55.6\%). The mean age of the included sample was 44.8 years, and $39.6 \%$ of the patients were older than 50 years. The Kingdom of Saudi Arabia is divided into five regions. Geographic distribution of the patients showed that among the included participants, 37 were from the central region, 13 were from the south region, six were from the east and west regions, and only one came from the north region. The demographic characteristics of the study participants are shown in Table 1.

According to our data, lumps were the most frequently occurring symptom in 49 patients followed by pain and facial nerve paralysis. According to the site of lesions, the majority of lesions originated from the parotid gland (47.6\%) followed by palate (20.6\%), submandibular gland (11.1\%), and $20.6 \%$ in other locations. In this study, an incisional biopsy was performed only in four patients. TNM staging of cancer showed that 27 patients were at stage IV, 11 were at stage III, 13 were at stage II, and 10 were at stage I. Histopathological examination of the tumors showed that the most frequent type of cancer is mucoepidermoid carcinoma presenting in $36.5 \%$ followed by adenoid cystic carcinoma (27\%), salivary duct carcinoma (9.5\%), acinic cell carcinoma, adenocarcinoma, epithelial-myoepithelial carcinoma (4.8\%), carcinoma ex-pleomorphic adenoma (3.2\%), squamous cell carcinoma (1.6\%). Recurrence of salivary gland cancer was present in 17 patients. The data of disease characteristics have been shown in Table 2 .

In the present study, old age, advanced stage of cancer, gender, and geographic location were considered as factors associated with the recurrence of salivary gland malignancy. Old age and gender were not associated with recurrence; however, the only factor associated with recurrence is the initial advanced stage of the tumor $(p=0.04)$, as shown in Table 3 . As per the geographic location, the frequency of recurrence in the central region was highest followed by the south, east, west, and north regions. 


\section{Cureus}

Demographic characteristics

Frequency

28

35

Male

Female

Region

Central

East

West

South

North

Age $>50$ years
44.4

Percentage (\%)

55.5

58.7

9.5

9.5

20.6

1.6

39.6

TABLE 1: Demographics characteristics of study participants

\begin{tabular}{|l|l|l|}
\hline \hline Factors & Frequency with recurrence & Frequency without recurrence \\
\hline Old age (>50 years) & 8 & 17 \\
\hline Advanced stage (III and IV) & 14 & 24 \\
\hline Gender (male) & 10 & 8 \\
\hline Geographic locations (Central-East-West-South-North) & $8-2-2-5-0$ & $29-4-4-8-1$ \\
\hline
\end{tabular}

TABLE 2: Factors associated with recurrent disease 


\section{Cureus}

\begin{tabular}{|c|c|c|}
\hline Disease characteristic & Frequency & Percent \\
\hline \multicolumn{3}{|l|}{ Presenting symptom } \\
\hline Pain & 5 & 7.9 \\
\hline Lump & 49 & 77.8 \\
\hline Facial nerve paralysis & 1 & 1.6 \\
\hline Other & 8 & 12.7 \\
\hline \multicolumn{3}{|l|}{ Site of lesion } \\
\hline Parotid & 30 & 47.6 \\
\hline Submandibular & 7 & 11.1 \\
\hline Palate & 13 & 20.6 \\
\hline Other & 13 & 20.6 \\
\hline Incisional biopsy performed & 4 & 6.5 \\
\hline \multicolumn{3}{|l|}{ Stage } \\
\hline 0 & 1 & 1.6 \\
\hline 1 & 10 & 16.1 \\
\hline II & 13 & 21 \\
\hline III & 11 & 17.7 \\
\hline IV & 27 & 43.5 \\
\hline \multicolumn{3}{|l|}{ Histopathology } \\
\hline Mucoepidermoid & 23 & 36.5 \\
\hline Adenoid cystic & 17 & 27 \\
\hline Acinic cell & 3 & 4.8 \\
\hline Carcinoma ex-pleomorphic adenoma & 2 & 3.2 \\
\hline Squamous cell $\mathrm{Ca}$ & 1 & 1.6 \\
\hline Adenocarcinoma & 3 & 4.8 \\
\hline Epithelial-myoepithelial carcinoma & 3 & 4.8 \\
\hline Salivary duct carcinoma & 6 & 9.5 \\
\hline Other & 5 & 7.9 \\
\hline nce of recurrenc & 17 & 27 \\
\hline
\end{tabular}

\section{TABLE 3: Disease characteristics of study participants}

\section{Discussion}

In this cross-sectional study, we attempted to identify the factors associated with the recurrence of salivary gland malignancy. Salivary gland malignancy is uncommon and having changeable behavior which makes the treatment difficult. Therefore, prediction of factors associated with recurrence makes treatment planning easier and increases the overall survival rate of the patients. The demographic distribution of this case-control study showed slightly more female distribution with the mean age of 44.4 years. In contrast, previous studies conducted by Feinstein MT et al. and Sheddi MAA showed a male predominance [21-22].

According to this study, a lump was the most frequent symptom (77.8\%) reported by patients. Similarly, Naami AL et al. found that a painless lump was a frequent manifestation observed in $71.8 \%$ of patients [23]. In the present study, the majority of malignancies originated from the parotid gland (47.6\%), and similar 
results were found by Feinstein MT et al. and Eneroth CM [21,24]. In our study, mucoepidermoid carcinoma (36.5\%) was the most common histologic variant followed by adenoid cystic carcinoma, salivary duct carcinoma, acinic cell, and adenocarcinoma. Similar results were replicated by Pinkston et al. [25]. On the contrary, a study by Feinstein MT et al. and Sheddi MAA identified adenoid cystic carcinoma as the most common histologic variant [21-22].

Our study found that the recurrence of salivary gland cancer is significantly associated with the TNM staging and higher recurrence rate was found in the initial advanced stages (III, IV) of cancer. Similar results were obtained by Jang JY et al. who presented that early-stage of disease (T1-2NOM0) showed apparently excellent prognosis and overall survival [26]. In contrast to previous studies, this study did not show a significant association between recurrence factors such as the age of patients, gender, and geographic location. Alkhateeb et al. reported that high predilection of mucoepidermoid carcinoma in minor salivary glands was associated with high female to male ratio, but recurrence does not depend upon gender [27]. Feinstein MT et al. showed that the age at the time of diagnosis had a significant relationship with overall survival $(p=0.01)$. However, age at diagnosis did not affect the risk of recurrence [21]. Due to the rarity and multiplicity of salivary gland cancers, the sample size of this study was small and hence, interpretation of the factors associated with the recurrence of salivary gland malignancies was quite challenging. Further study with larger sample size is recommended. The limitation of this study is a small sample size but this due to low incidence rate of the salivary glands cancer .

\section{Conclusions}

The initial advanced stage of cancer has a pivotal role in the recurrence of salivary gland malignancy. As salivary gland malignancy is rare with an unreliable biological behavior, its treatment remains challenging. Although our study did not show the association between recurrence and gender or old age, these factors were shown to be associated with the re-emergence of salivary gland malignancy in other studies, including the initial stage of cancer, age, gender, and geographic location. Therefore, for effective treatment planning, prediction of factors associated with the recurrence of salivary gland malignancy is mandatory.

\section{Additional Information \\ Disclosures}

Human subjects: Consent was obtained by all participants in this study. King F ahad Medical City issued approval IRB number :18-192E. approved according TO ICH GCP guidelines . Animal subjects: All authors have confirmed that this study did not involve animal subjects or tissue. Conflicts of interest: In compliance with the ICMJE uniform disclosure form, all authors declare the following: Payment/services info: All authors have declared that no financial support was received from any organization for the submitted work. Financial relationships: All authors have declared that they have no financial relationships at present or within the previous three years with any organizations that might have an interest in the submitted work. Other relationships: All authors have declared that there are no other relationships or activities that could appear to have influenced the submitted work.

\section{References}

1. Parkin DM1, Ferlay J, Curado MP, Bray F, Edwards B, Shin HR, Forman D: Fifty years of cancer incidence: CI5 I-IX. Int J Cancer. 2010, 127:2918-2927.

2. Spiro RH: Salivary neoplasms: overview of a 35-year experience with 2,807 patients . Head Neck Surg. 1986, 8:177-84.

3. de Ridder M, Balm AJ, Smeele LE, Wouters MW, van Dijk BA: An epidemiological evaluation of salivary gland cancer in the Netherlands (1989-2010). Cancer Epidemiol. 2015, 39:14-20.

4. Ettl T, Schwarz-Furlan S, Gosau M, Reichert TE: Salivary gland carcinomas. J Oral Maxillofac Surg. 2012, 16:267-83.

5. Pathology and Genetics of Head and Neck Tumours . WHO Classification of Tumours, 3rd Edition. Barnes L, Eveson JW, Reichart P, Sidransky D (ed): IARC Publications, Lyon, France; July 25, 2019. 9:210-280.

6. Terhaard CH, Lubsen H, Van der Tweel I, et al.: Salivary gland carcinoma: independent prognostic factors for locoregional control, distant metastases, and overall survival: results of the Dutch head and neck oncology cooperative group. Head Neck. 2004, 26:681-92.

7. Licitra L, Grandi C, Prott FJ, Schornagel JH, Bruzzi P, Molinari R.: Major and minor salivary glands tumors . Crit Rev Oncol Hematol. 2003, 45:215-25. 10.1016/S1040-8428(02)00005-7

8. Nance MA, Seethala RR, Wang Y, Chiosea SI, Myers EN, Johnson JT, Lai SY: Treatment and survival outcomes based on histologic grading in patients with head and neck mucoepidermoid carcinoma. Cancer. 2008, 113:2082-9. 10.1002/cncr.23825

9. Horn-Ross PL, Morrow M, Ljung BM.: Diet and the risk of salivary gland cancer . Am J Epidemiol. 1997, 146:171-176. 10.1093/oxfordjournals.aje.a009248

10. Horn-Ross PL , Ljung BM, Morrow M.: Environmental factors and the risk of salivary gland cancer . Epidemiology. 1997, 8:414-419.

11. Swanson GM, Burns PB: Cancers of the salivary gland: workplace risks among women and men . Ann Epidemiol. 1997, 7:369-374.

12. Dong C, Hemminki K: Second primary neoplasms among 53159 haematolymphoproliferative malignancy patients in Sweden, 1958-1996: a search for common mechanisms. Br J Cancer. 2001, 85:997-1005.

13. Sun EC, Curtis R, Melbye M, Goedert JJ: Salivary gland cancer in the United States. Cancer Epidemiol 
Biomarkers. 1999, 8:1095-1100.

14. Adelstein DJ, Koyfman SA, El-Naggar AK, Hanna EY: Biology and management of salivary gland cancers . Semin Radiat Oncol. 2012, 22:245-53. 10.1016/j.semradonc.2012.03.009

15. Shishegar M, Ashraf MJ, Azarpira N, Khademi B, Hashemi B, Ashrafi A: Salivary gland tumors in maxillofacial region: a retrospective study of 130 cases in a southern Iranian population. Patholog Res Int. 2011, 2011:934350. 10.4061/2011/934350

16. Bello IO, Salo T, Dayan D, et al.: Epithelial salivary gland tumors in two distant geographical locations, Finland (Helsinki and Oulu) and (Tel Aviv): a 10-year retrospective comparative study of 2,218 cases. Head Neck Pathol. 2012, 6:224-31. 10.1007/s12105-011-0316-5

17. Tilakaratne WM, Jayasooriya PR, Tennakoon TM, Saku T: Epithelial salivary tumors in Sri Lanka: a retrospective study of 713 cases. Oral Surg Oral Med Oral Pathol Oral Radiol Endod. 2009, 108:90-8. 10.1016/j.tripleo.2009.01.026

18. Tian Z, Li L, Wang L, Hu Y, Li J: Salivary gland neoplasms in oral and maxillofacial regions: a 23-year retrospective study of 6982 cases in an eastern Chinese population. Int J Oral Maxillofac Surg. 2010, 39:23542. 10.1016/j.ijom.2009.10.016

19. Buchner A, Merrell PW, Carpenter WM: Relative frequency of intra-oral minor salivary gland tumors: a study of 380 cases from northern California and comparison to reports from other parts of the world. J Oral Pathol Med. 2007, 36:207-14. 10.1111/j.1600-0714.2007.00522.x

20. Amin MB, Edge S, Greene F, et al.: AJCC Cancer Staging Manual (8th edition). Amin MB, Edge S, Greene F, Byrd DR, Brookland RK, Washington MK, Gershenwald JE, Compton CC, Hess KR, et al. (Eds.) (ed): American Joint Commission on Cancer, Springer International Publishing; 2017.

21. Trevor M. Feinstein, Stephen Y. Lai, Diana Lenzner, et al.: Prognostic factors in patients with high-risk locally advanced salivary gland cancers treated with surgery and postoperative radiotherapy. Head Neck. 2011, 33:318-323. 10.1002/hed.21444

22. Sheddi MAA: Salivary glands tumors: a single institution experience in Saudi Arabia . Biotech Res Asia. 2012, 9:1.

23. Al-Naami MY, Guraya SY, Arafah MM, Al-Zobydi AH, Al-Tuwaijri TA: Clinicopathological pattern of malignant parotid gland tumors in Saudi Arabia. Saudi Med J. 2008, 29:413-7.

24. Eneroth CM.: Salivary gland tumors in the parotid gland, submandibular gland, and the palate region . Cancer. 1971, 27:1415-8. 10.1002/1097-0142(197106)27:6<1415::aid-cncr2820270622>3.0.co;2-x

25. Pinkston JA, Cole P: Incidence rates of salivary gland tumors: Results from a population-based study . Otolaryngol Head Neck Surg. 1999, 120:834-40. 10.1016/S0194-5998(99)70323-2

26. Jeon Yeob Jang, Nayeon Choi, Young-Hyeh Ko, et al.: Treatment outcomes in metastatic and localized highgrade salivary gland cancer: high chance of cure with surgery and postoperative radiation in T1-2 N0 highgrade salivary gland cancer. BMC Cancer. 2018, 18:672. 10.1186/s12885-018-4578-0

27. Al-Khateeb TH, Ababneh KT: Salivary tumors in north Jordanians: a descriptive study . Oral Surg Oral Med Oral Pathol Oral Radiol Endod. 2007, 103:53-59. 10.1016/j.tripleo.2006.11.017 